\title{
Characteristic Analysis on Swelling-shrinkage Grade of Expansive Soil Zhan-Bin WANG ${ }^{a,{ }^{*}}$, Bin HUANG $^{b}$, Fan TAN ${ }^{c}$, Yan-Yong XU ${ }^{d}$ \\ ${ }^{1}$ Yangtze River Scientific Research Institute, Key Laboratory of Geotechnical Mechanics and Engineering of The Ministry of Water Resources, Wuhan 430010, China \\ ${ }^{2, *}$ Postgraduate in Geoengineering Department of Soil Engineering, Yangtze River Scientific Research Institute, Wuhan, China

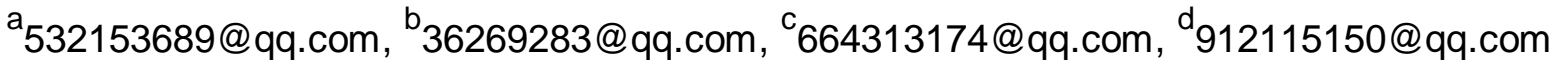 \\ ${ }^{*}$ Corresponding author
}

Keywords: Characterization, Expansive Soil, Fuzzy Sets, Fuzzy C Means Algorithm.

\begin{abstract}
Relying on North Water Transfer Project, the physical and mechanical indexes that reflect the characterization of expansive soil mechanism and characteristics are deeply investigated. Arming to uncertainty, noise and multi-modal in general experimental of expansive soil, fuzzy sets are introduced to clustering and traditional hard clustering objective function is extended to fuzzy clustering criterion function, then a flexible fuzzy $\mathrm{C}$ means algorithm are constituted. Applicability of algorithm for identification and classification of multiple targets is studied to search for a reasonable classification criteria.
\end{abstract}

\section{Introduction}

The Central Project of Water Adjustment from South to North, with complicated engineering geological engineering geological condition, is located at the special soil area of the loess, expansive soil and potential liquefaction sand. The length of main channel is $1427 \mathrm{~km}$, among which, the open channel whose slope and bottom involves expansive soil has a length of $340 \mathrm{~km}$. Due to special engineering properties of expansive soil, which makes the slope instability to the case of channel slope happen, the disease affect seriously natural mange and benefit exert of channel. Fig.1 presents the experimental canal's instability conditions of the Central Project after the artificial rainfall. This kind of engineering phenomenon exerts a tremendous influence on the safe running of engineering, and its handling difficulty, engineering quantities and investment in it are unimaginable. Consequently, the treatment of expansive soil is one of the key technical problems.

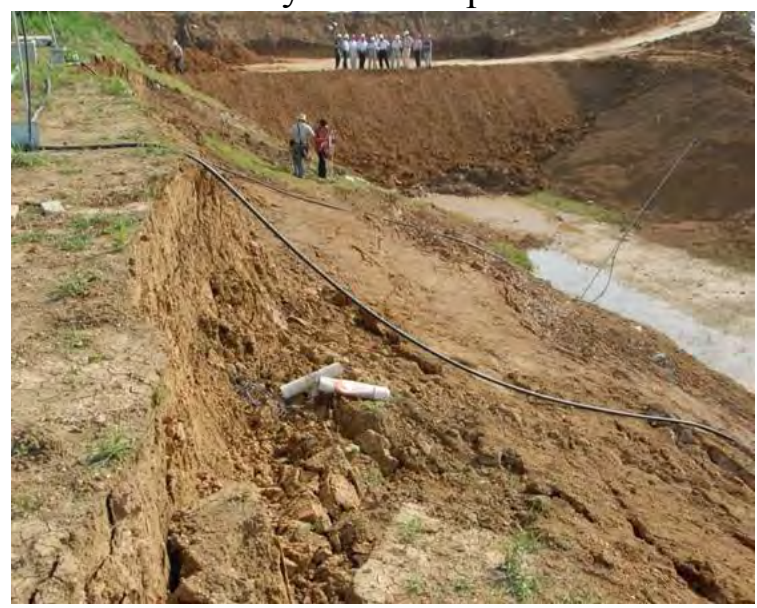

(a) The experimental canal with middle expensive soil

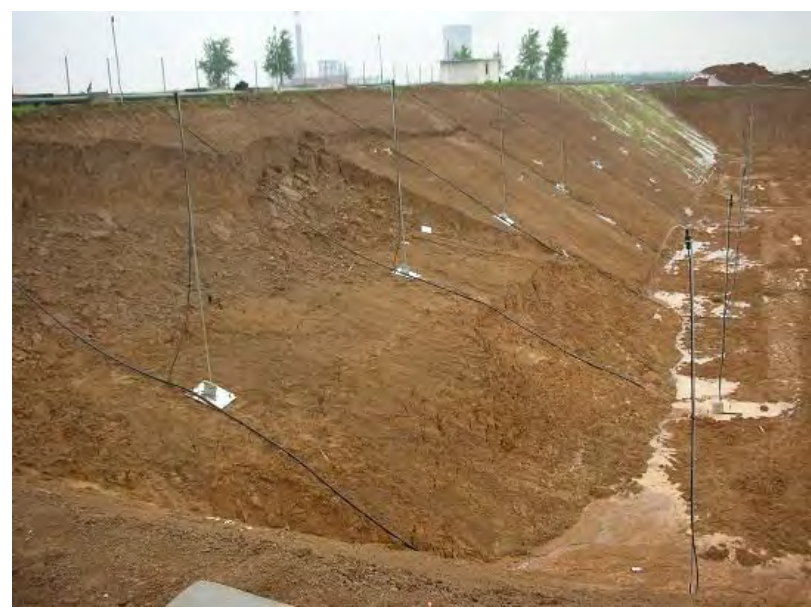

(b) The experimental canal with weak expensive soil

Fig. 1 the Experimental Canal's Slope Instability Conditions of the Central Project

There are a lot of methods for the classification of swelling shrinkage grade of expansive soil. Amon them, the classification by air-dried moisture content [1], plasticity chart [2], and so on are the traditional method. The clay expansion potential classification graph was developed by Williams [3] who plotted the 
plasticity index (liquid limit minus plastic limit) against clay content $(\leq 2 \mu \mathrm{m})$. The free swelling ratio classification, in technical code for building in swelling soil zone (GB112-87) [4], has many disadvantages in theory and engineering practice and is unavailable for regions involved complex geographical factors due to its great variation in different areas with different density of soil. The expanded and shrink potential index was adopted by Zui-jing KE [5] in 1980 to identify and classify expansive soil. Many scholars put forward the integrated multiindex classification methods as a result of a number of factors that affect the expansion and shrink characteristics of expansive soil. Kai-yun CHEN [6] put forward a multiple linear function of integrated index through dimensional analysis and stepwise regression analysis by means of mathematical statistics. And Hai-lin Yao and others [7] advised that the classification of expansive soil could be adopted by the 3 indexes (free swelling rate, plasticity index and standard absorption moisture) based on the experimental study of the linear relationship between standard absorption moisture and the CEC (cation exchange capacity), the montmorillonite content, specific surface area. Today, the multiindex function identification and classification is being attached more attention in the engineering circles [8-11]. And some scholars advised that the classification of expansive soil could combine the multiindex with neural network, grey theory and expert system.

This paper presents the classification of Nanyang expansive soil by using FCM algorithm rely on the Central Project of Water Adjustment from South to North and analyzes the usability of multiindex classification and sort algorithm, and gives the logical grading criteria.

\section{The Basic Physical Characteristic of Nanyang Expansive Soil}

The quaternary expansive soil was in majority in the Central Project of Water Adjustment from South to North. The expansive soil distributed mainly in the Taofen-Beiru river reach, Huixian-Xinxiang river reach and Handan-Xingtai River reach, scatterly in the two banks of Ying River and Xiaonan River, the southern part of Qi River - Hong River, Nanshiwang-Hong River, Shijiazhuang, Gaoyi and other places. According to the engineering geological exploration, there are 184 canal reaches of general main canal, including the canal slope and canal bottom. The cumulative length is $335 \mathrm{~km}$, which includes $6 \mathrm{~km}$ of strong expansive soil canal, $103 \mathrm{~km}$ of middle expansive soil canal and $170 \mathrm{~km}$ of weak expansive soil canal.

According to the basic physical-mechanical property test results of the samples from the Nanyang test section of the Central Project of Water Adjustment from South to North, the particle diameter of the involved expansive soil is not more than $5 \mu \mathrm{m}$, clay and colloid content is between $10 \%-50 \%$, and free swelling ratio is between $40 \%-90 \%$. The Nanyang silty clay is mainly divided into middle expansive soil and weak expansive soil [4]. And the mineral chemical composition is mentioned in Table 1.

Tab. 1 the Mineral Chemical Composition of Nanyang Expansive Soil

\begin{tabular}{ccccc}
\hline Soil types & $\begin{array}{c}\text { Clay } \\
(\%)\end{array}$ & $\begin{array}{c}\text { Montmorillonite } \\
(\%)\end{array}$ & $\begin{array}{c}\text { Cation exchange capacity } \\
(\mathrm{meq} / 100 \mathrm{~g})\end{array}$ & $\begin{array}{c}\text { Insoluble } \\
\text { salts (\%) }\end{array}$ \\
\hline $\begin{array}{c}\text { Nanyang weak } \\
\text { expansive soil }\end{array}$ & 25.0 & 11.8 & 23.7 & 0.1 \\
$\begin{array}{c}\text { Nanyang middle } \\
\text { expansive soil }\end{array}$ & 23.5 & 10.8 & 29.7 & 1.6 \\
\hline
\end{tabular}

The figure in the table is average.

There is not much difference between Nayang middle expansive soil and weak expansive soil in montmorillonite content and clay content from mineral composition, but the swelling-shrinkage behavior of them varies greatly. This is because the swelling-shrinkage behavior is not only up to montmorillonite content and clay content, but also the calcite content of mineral composition and insoluble salts content of chemical composition. Consequently, the single criteria index of montmorillonite content, calcite content, or others for assessing the swelling-shrinkage potential of expansive soil is unreasonable, and the other embodiment is the properties of uncertainty, noisy and multimode of the swelling-shrinkage potential. 


\section{The Fuzzy C-Means Clustering Algorithm with Two Stages}

\section{The Fundamental Principles of Fuzzy C-Means Clustering Algorithm}

The ordinary C-Means algorithm to implement the partition of data is hard and fast algorithm. According to the properties of uncertainty, noisy and multimode of the expansive soil in the routine test, to get a kind of flexible partition method- the fuzzy C-Means clustering algorithm, the fuzzy set is introduced in cluster analysis, and the ordinary hard and fast clustering target function is expanded into fuzzy clustering criterion function.

$\mathrm{N}$ vectors is divided into $\mathrm{C}$ ambiguity groups in the fuzzy $\mathrm{C}$-Means clustering algorithm, and the clustering center of each ambiguity group could be calculated to minimize the value function of non-similarity indexes, and be appropriate to the fuzzy partition. The element of membership matrixes $U$ is limited to the interval $(0,1)$, and also satisfy the normalized principle, which requires that the summary of the data set degree of membership of each index should be 1 . The given finite data points could be represented by $X=\{x 1, x 2, \ldots, x n\} \subset R S$. The partition of fuzzy $C$ could be expressed by membership matrix $U=[u i j] n \times c$, where the element uij is the membership degree of the $i t h(i=1,2, \ldots, n)$ data point to the $\mathrm{jth}(\mathrm{j}=1,2, \ldots, \mathrm{c})$ category, and uij should meet the following condition.

$$
\forall i, j \quad u_{i j} \in[0,1] ; \forall i \quad \sum_{j=1}^{c} u_{i j}=1
$$

The partition of fuzzy C was reduced, by Bezdek [12], to extremum of the sum of error square in the overall group on above constrained conditions.

$$
\min J_{w}(U, V)=\sum_{i=1}^{n} \sum_{j=1}^{c} u_{i j}{ }^{m}\left\|x_{i}-v_{j}\right\|^{2}
$$

Where the membership matrix $U=[u i j] n \times c$, and $V=(v 1, v 2, \cdots, v c), v j(j=1,2, \cdots, c) \in R S$ means the jth cluster center. The fuzzy weighted index m controls the fuzzy possibility that the fuzzy possibility is gathering with the increasing $\mathrm{m}$ value. Pal and Bezdek[13] advised that the selection range of reasonable $\mathrm{m}$ value was $[1.5,2.5] . \mathrm{Jw}(\mathrm{U}, \mathrm{V})$ is the weighted sum of squares of the length from every data point to corresponding cluster center. Because the vi means square-error of xi, uijm $\|$ xi-vj $\| 2$ could be considered as the dimension of local density. FCM algorithm is an iteration method to minimize the target function $\mathrm{Jw}(\mathrm{U}, \mathrm{V})$. It starts from a random cluster center, and adjusts the fuzzy membership degree to determine the categories by searching for minimum point of the target function.

The above problem of fuzzy clustering could be changed into optimally solving the expression (2) with the constraint condition (1). The equations of $\mathrm{U}, \mathrm{V}$ values are derived by Lagrange multiplier method [14].

$$
\begin{gathered}
u_{i j}=\left(\sum_{k=1}^{c}\left(\left\|x_{i}-v_{j}\right\| /\left\|x_{i}-v_{k}\right\|\right)^{2 /(m-1)}\right)^{-1} \\
(1 \leq i \leq n, 1 \leq j \leq c) \\
v_{j}=\sum_{i=1}^{n} u_{i j}{ }^{m} x_{i} / \sum_{i=1}^{n} u_{i j}{ }^{m} \quad(1 \leq j \leq c)
\end{gathered}
$$

In the FCM algorithm, an initial clustering center could be chosen randomly. The categories and clustering center are adjusted from expression (3) and (4) for each iteration until the calculated clustering centers in adjacent iterations have a close agreement. And the algorithm convergence could be concluded.

Each iteration minimizes the target function $\mathrm{Jw}(\mathrm{U}, \mathrm{V})$ in this algorithm, and $\mathrm{Jw}(\mathrm{U}, \mathrm{V})$ could have many extreme points. If the initial clustering center was chosen around a local extreme point, the algorithm could have a convergence to local extreme. In other words, FCM algorithm is sensitive to initial values, and the data processing result maybe not good. For that reason, some scholars improve the FCM algorithm by changing the selection of initial clustering center randomly into a destination choice to 
guarantee obtaining the globally optimal solution [15]. After all data samples have been divided into C categories, the jth initial clustering center could be represented as the following equation.

$$
v_{j}=\frac{1}{n_{j}} \sum_{x_{j} \in j} x_{j}
$$

Where $n_{j}$ is the numbers of data points involved in the $j_{\text {th }}$ category.

\section{The Calculation Process of Fuzzy C-Means Clustering Algorithm}

In the first stage of the algorithm, the rough clustering samples are based on similarity the threshold value and the minimum distance principle, and the clustering center is obtained in its calculations. In the second stage of the algorithm, the standard FCM algorithm operated with the initial clustering center of the results calculated in the first stage.

In summary, the following is the specific flow of the FCM algorithm.

Step 1. Calculating the Euclidean distance between the random two sample points, choosing the sample which has the closest distance from the threshold value $\kappa$, and all of samples in the range of $\kappa$ distance around both two samples falling into the category are the main contents of this step.

Step 2. The two samples, the closest samples in the rest of them, are classified as a category if they have a greater distance than $\kappa$. Otherwise, the distance threshold value should be reset to $\kappa^{\prime}=\alpha \kappa(0<\alpha<1)$, and all of the samples belong to the category in the range of $\kappa^{\prime}$ distance from either of them.

Step 3. This step restarts the process of the step 2 until all samples are classified. On another occasion, the only one last should be a category lonely.

Step 4. Adjusting the $\kappa, \kappa^{\prime}$ values is needed until all samples are clustered into $\mathrm{C}$ categories. The clustering center of each category, $v j(j=1,2, \cdots, C)$. is calculated by Equation (5).

Step 5. This step is to set $m \in[1.5,2.5]$ and $c \in\{2,3, \cdots, n-1\}$ according to the given data set $X=\{x 1$, $\mathrm{x} 2, \cdots, \mathrm{xn}\} \subset \mathrm{RS}$, choose a constant $\varepsilon>0$, and initialize the matrix $\mathrm{Un} \times \mathrm{c}(0)$ with a random constant between 0 and 1 while satisfying the limit condition equation (1).

Step 6 . While the number of iterations is $1(1=0,1,2, \cdots), \mathrm{C}$ clustering centers, ci $(\mathrm{i}=1,2, \cdots, \mathrm{C})$ are being calculated by Equation (5).

Step 7. $U(1)=\operatorname{uij}(1)$ is updated for $U(1+1)=\operatorname{uij}(1+1)$.

Step 8. If $\|U(1+1)-U(1)\|<\varepsilon$, the fuzzy clustering results would be obtained. Otherwise, this step sets $1=1+1$ and goes back to step 6 .

The output of the algorithm is $\mathrm{C}$ clustering center point vectors and $\mathrm{n} \times \mathrm{c}$ fuzzy partition matrixes, which is the membership degree of each sample point belonging to each category. Based on the partition matrix, the types of categories are defined by the maximum membership principle. The clustering centers are the average characteristics of each category and the representative points.

\section{Conclusion}

Based on the Central Project of Water Adjustment from South to North, the in-depth exploration of physical and mechanical indexes reflecting the swelling and shrinking mechanism and characteristics promotes swelling potential classification of Nanyang expansive soil.

(1) The basic physical and mechanical characteristics, swelling-shrinkage properties libarotary are conducted according to samples from Nanyang. The Nanyang silty clay is mainly divided into middle expansive soil and weak expansive soil.

(2) There is not much difference between Nayang middle expansive soil and weak expansive soil in montmorillonite content and clay content from mineral composition, but the swelling-shrinkage behavior of them varies greatly. And the single criteria index of montmorillonite content, calcite content, or others for assessing the swelling-shrinkage potential of expansive soil is unreasonable, and the other embodiment is the properties of uncertainty, noisy and multimode of the swelling-shrinkage potential.

(3) According to the properties of uncertainty, noisy and multimode of the expansive soil in the routine test, to get a kind of flexible partition method- the fuzzy C-Means clustering algorithm, the fuzzy set is introduced in cluster analysis. 


\section{References}

[1]Luo-rong TAN, Hai-ying ZHANG, Wu-min SHAO, et al. The practicability research on use of air dry moisture content W65 as identification index of swelling soil, Journal of Engineering Geology, 2(1994)15-26.

[2]Gui-zhi MA, The application of plasticity chart to Shanxi special soils distribution, Journal of Xi'an College of Geology. 17(1995)87-89.

[3]Williams A A B, Donaldson G, Building on expansive soils in South Africa, Proceedings of 4th International Conference on Expansive Soils, Denver, Colorado. 2(1980)834-838.

[4]Ministry of Housing and Urban-Rural Development of the People's Republic of China, Technical code for buildings in expansive soil regions(GBJ112-87), China Planning Press, Beijing, 2003.

[5]Zun-jing KE, The discrimination and evaluation of expansive soil by swelling-shrinkage potential index, industrial construction, Beijing, 1980.

[6]Te-hong LIU, Problems of Expansive Soils in Engineering Construction, China Architecture and Building Press, Beijing, 1997.

[7]Hai-lin YAO, Ping CHENG, Yang YANG, et al., Testing study on moisture water content of standard absorption for expansive soil, Science in China(Ser.E), 35(2005)43-52.

[8]X. S. SHI, Z. L. CHENG, Fuzzy C-Means Algorithm on Identifying Grade of Expansive Soil, Proceedings of the third international conference on modeling and simulation, Wuxi, (2010)180-183.

[9]Yu-hua LI, Xiao-la FENG, Ying-zheng YAN. Application of gray clustering procedure to classification of expansive soils, Rock and Soil Mechanics, 24(2003)304-306.

[10]Shun-min YIN, Tong-Zhen YAN, Artificial neural network method for discrimination and classification of expansive soil, Geological Science and Technology Information, 14(1995)91-94.

[11]Wen-tao MA, Application of support vector machine to classification of expansive soils, Rock and Soil Mechanics, 26(2005)1790-1795.

[12]Bezdek J. C., Pattern Recognition with Fuzzy Objective Function Algorithms, Plenum Press, New York, 1981.

[13]Pal N. R., Bezdek J. C., On clusters validity for the fuzzy C means mode, IEEE Trans. on Fuzzy Systems, 28(1995)370-379.

[14]Li-xin WANG, A Course in Fuzzy System and Control, Tsinghua University Press, Beijing, 2003.

[15]Xin-bo ZHANG, Fuzzy C Means clustering algorithm with two stages, Journal of circuits and systems, 10(2005)117-120. 